\title{
Evaluation of three automated methods for the extraction of circulating DNA: application to the diagnosis of mucormycosis by q-PCR
}

Cornu, M. 1,2, Guerin, M. ${ }^{2}$, Leroy, J. 1,2, Galichet, S. ${ }^{3}$, Hallaert, C. ${ }^{3}$, Sendid, B ${ }^{1,2}$

${ }_{1}$ Univ. Lille, INSERM UMR 995 - LIRIC - Lille Inflammation Research International Center, F-59000 Lille, France, ${ }^{2} \mathrm{CHU}$ Lille, Service de Parasitologie-Mycologie, F-59000 Lille, France, ${ }^{3}$ CHU Lille, Institut de Microbiologie, CHU Lille, F-59000 Lille, France

Objectives. Mucormycosis $(\mathrm{MM})$ is a rare invasive fungal infection caused by environmental moulds of the order of Mucorales, whose incidence has increased over the past decade. This infection affects mainly immunosuppressed patients and is associated with a poor prognosis. The diagnosis, previously based solely on conventional mycological examination, has been improved by the detection of circulating Mucorales DNA by q-PCR. The yield of DNA extracted remains a critical issue for Mucorales DNA detection in blood. Our objective was to compare currently available automated methods for DNA extraction from serum in patients with MM.

Methods. The Applied Biosystems ${ }^{\circledR} 7500$ Real-Time PCR System, whose performance has been evaluated previously as similar to the LightCycler® 480 Instrument, was used for DNA amplification. We compared three automated methods designed for circulating DNA extraction: (i) MICROLAB STARlet instrument (Hamilton $\AA$ ) coupled with a NucleoSpin® 96 DNA plasma kit (Macherey-Nagel); (ii) AutoMag instrument coupled with a MycoGENIE® Af DNA kit (Ademtech); and (iii) MagNA Pure Compact Instrument coupled with a Large Volume MagNA Pure Nucleic Acid Isolation kit (Roche). Depending on the method used, the volume of sample varies from $200 \mu \mathrm{L}$ to $1 \mathrm{~mL}$.
The first method uses a silica membrane, whereas the other two use magnetic beads to extract DNA. Analysis was performed on both clinical (39 sera sequentially collected from 14 patients with MM) and spiked blood samples. q-PCR was performed as described previously (Millon et al. CID. 2013).

Results. The yield of DNA extracted by all test procedures was very similar, with a better limit of detection (LoD) for the Roche and Hamilton/Macherey-Nagel methods $(<1 \mathrm{fg} / \mu \mathrm{l})$ (Table 1). The cost per DNA extraction varied from $5 €$ (Ademtech) to $20 €$ (Roche), whereas the estimated extraction time was 1-3 $\mathrm{h}$ with the MICROLAB STARlet system (Table 2). For clinical samples, q-PCR was positive in 8/14 patients with $\mathrm{MM}$ and for 7 of them q-PCR could have reduced the time to diagnosis in comparison to mycological methods (up to 17 days) (Table 3). All q-PCR positive results were concordant with mycological identification. q-PCR also revealed a co-infection with two different Mucorales species. The sensitivity of q-PCR was $61.5 \%$ and most negative results were observed in patients who were tested after initiation of antifungal therapy and/or presented with cutaneous MM. The analytical performance of this method has been validated through external quality assurance samples distributed by the PHRC ModiMucor/FPCRI Muc Lab working group.

Table 1. Limits of detection after different DNA extraction methods

\begin{tabular}{|cccc|}
\hline DNA & \multicolumn{3}{c|}{ Kit of extraction (median Cq) } \\
concentration & Ademtech & Macherey Nagel & Roche \\
\hline $50(\mathrm{fg} / \mu \mathrm{l})$ & 33,75 & 30,85 & 30,45 \\
$10(\mathrm{fg} / \mu \mathrm{l})$ & 35,3 & 32,15 & 32,85 \\
$5(\mathrm{fg} / \mu \mathrm{l})$ & 36,05 & 34,4 & 34,05 \\
$1(\mathrm{fg} / \mu \mathrm{l})$ & 37,15 & 35,35 & 36,05 \\
$0,25(\mathrm{fg} / \mu \mathrm{l})$ & undetectable & $35,7^{*}$ & $36,8^{*}$ \\
\hline
\end{tabular}

Table 3. Results of the retrospective clinical study

\begin{tabular}{|lcc|}
\hline & \multicolumn{2}{c|}{ Kit of DNA extraction } \\
& Ademtech & Macherey-Nagel \\
\hline 2 positive replicates & 11 & 13 \\
1 positive replicate & 5 & 2 \\
number of positive serum & 16 & 15 \\
number of positive patient & 8 & 8 \\
\hline
\end{tabular}

Table 2. Technical features of the different extraction kits and instruments

\begin{tabular}{|c|c|c|c|}
\hline Kit of DNA extraction & $\begin{array}{c}\text { Large Volume MagNA Pure } \\
\text { Nucleic Acid Isolation (Roche) }\end{array}$ & $\begin{array}{c}\text { NucleoSpin® } 96 \text { DNA plasma } \\
\text { (Macherey-Nagel) }\end{array}$ & $\begin{array}{l}\text { MycoGENIEß Af DNA } \\
\text { (Ademtech) }\end{array}$ \\
\hline Instrument & MagNA Pure Compact (Roche) & MICROLAB STARlet (Hamilton®) & AutoMag Solution (Ademtech) \\
\hline Method & Magnetic beads & Silica membrane & Magnetic beads \\
\hline Sample volume & $1 \mathrm{~mL}$ & $1 \mathrm{~mL}$ & $200 \mu \mathrm{L}$ \\
\hline Time of total process & $60 \mathrm{~min}$ & $3 \mathrm{~h}$ & $60 \mathrm{~min}$ \\
\hline Min-max number of samples per run & $1-8$ & $8-24$ & 12 \\
\hline Dimensions $(\mathrm{cm})$ & $54 \times 61 \times 57$ & $112.4 \times 79.5 \times 90.3$ & $40 \times 46 \times 35$ \\
\hline Approximative cost per samples & $20 €$ & $12 €$ & $5 €$ \\
\hline Pros & $\begin{array}{c}\text { Easy use } \\
\text { Fast } \\
\text { Sensitivity }\end{array}$ & $\begin{array}{c}\text { Easy use (adaptation time) } \\
\text { Sensitivity } \\
\text { Automatisation of the } \\
\text { whole pre-PCR process }\end{array}$ & $\begin{array}{c}\text { Easy use } \\
\text { Fast } \\
\text { Cost }\end{array}$ \\
\hline Cons & Cost & Time of process & $\begin{array}{c}\text { Sensitivity } \\
12 \text { samples minimum }\end{array}$ \\
\hline
\end{tabular}

Conclusion. Our study showed that the MICROLAB STARlet system coupled with a NucleoSpin® 96 DNA plasma kit (MachereyNagel) and AB7500 real-time PCR system represents a suitable method combining the technical, economic and clinical requirements for the reliable diagnosis of MM. 